\title{
Contraceptive practices and pregnancy intendedness among pregnant adolescents
}

\author{
This article was published in the following Dove Press journal: \\ International Journal of Women's Health \\ 20 March 2015 \\ Number of times this article has been viewed
}

\section{Wakul Lanjakornsiripan \\ Siriruthai Amnatbuddee \\ Kanok Seejorn \\ Yuthapong Werawatakul \\ Pilaiwan Kleebkaow \\ Ratana Komwilaisak \\ Sanguanchoke \\ Luanratanakorn \\ Department of Obstetrics and Gynaecology, Faculty of Medicine, Khon Kaen University, Khon Kaen, Thailand}

Background: Adolescent pregnancy is a major health problem in many developing countries.

Objective: To assess contraceptive practices and pregnancy intendedness in pregnant adolescents.

Materials and methods: This study was prospectively conducted from September 2013 to June 2014. All consecutively pregnant women between 15 and 19 years old attending the Antenatal Clinic at Srinagarind Hospital and the Khon Kaen Branch of the Planned Parenthood Association of Thailand were invited for participation. Face-to-face interviews by trained interviewers using standardized questionnaires were carried out. Logistic regression was used to determine an adjusted odds ratio (aOR) and 95\% confidence interval (CI) of independent predictors.

Results: Two hundred participants were enrolled. Mean age was 17.2 years. One hundred and eighteen $(59.0 \%)$ were currently in school. Seventy-five $(37.5 \%)$ participants had never used any contraceptive methods. Of the 125 participants who had ever used contraception, regular use of contraceptives was reported in only 21 participants (16.8\%). Only two participants $(1.0 \%)$ had ever used an intrauterine device or implant. Participants' age was a significant independent factor associated with non-use of contraceptives (aOR, 6.42; 95\% CI, 2.94-14.04). Of the 200 participants, $132(66.0 \%)$ declared that the pregnancy was unintended. Significant independent factors predicting unintended pregnancy were educational status (aOR, 6.17; 95\% CI, 3.27-13.75) and participants' age (aOR, 5.76; 95\% CI, 2.42-13.70).

Conclusion: Non-use and use of contraceptive methods with high failure rates were major reasons leading to adolescent pregnancies. Participants' age was an independent factor predicting non-use of contraceptives. Educational status and age of the participants were significant factors predicting unintended pregnancy.

Keywords: contraception, unintended pregnancy, teenage pregnancy

\section{Introduction}

Adolescent pregnancy is a major public health problem in many developing countries. In a recent multicountry survey conducted by the World Health Organization, the rate of Thai adolescent births was 117 per 1,000 deliveries. ${ }^{1}$ Previous studies among pregnant adolescents have reported an increased risk of adverse maternal and perinatal outcomes including maternal anemia, preterm delivery, low birth weight, and rate of neonatal admission to an Intensive Care Unit. ${ }^{2-5}$ Additionally, a substantial number of pregnancies occurring in adolescents are unintended and might be terminated; these terminations may result in serious morbidity and mortality. ${ }^{6}$ Thus, adolescent pregnancy not only increases the risk of adverse pregnancy outcomes, but also negatively impacts the quality of life of the parents and infants. Designing and implementing effective contraception services for reducing adolescent pregnancy therefore is of utmost importance.
Correspondence: Siriruthai Amnatbuddee Department of Obstetrics and Gynaecology, Faculty of Medicine, Khon Kaen University, Khon Kaen, 40002 Thailand

Tel +6643363029

Fax+6643348395

Emails_auang@hotmail.com 
As the pattern of contraceptive practice can be situationspecific, the pattern depends on the quality of medical services, the level of functional health literacy, and women's social and cultural backgrounds. ${ }^{7-9}$ It is therefore important to determine the area-specific data regarding contraceptive practices and pregnancy intendedness. Accordingly, this study was conducted to assess pregnancy intendedness and previous contraceptive practice among Thai pregnant adolescents.

\section{Materials and methods}

This descriptive study was approved by the Research Ethics Committee of the Faculty of Medicine, Khon Kaen University, Khon Kaen, Thailand. This study was prospectively conducted from September 2013 to June 2014. All consecutively pregnant women between 15 and 19 years old attending the Antenatal Clinic at Srinagarind Hospital and the Khon Kaen Branch of the Planned Parenthood Association of Thailand were invited for study participation.

As no study has been conducted to determine the prevalence of unintended pregnancy among Thai pregnant adolescents, we calculated a sample size at $50 \%$ prevalence of unintended pregnancy, which represents the largest sample size required. At a level of $10 \%$ precision and $95 \%$ of the confidence interval $(\mathrm{CI})$, the estimated number of pregnant adolescent required was at least 96.

Informed consent was obtained from each participant recruited in this study. Face-to-face interviews by trained, female nurses using standardized questionnaires were carried out. Detailed information elicited from participants included baseline characteristics, previous contraceptive use, source of contraceptive information, and their retrospective intention to be pregnant. The questionnaire was piloted in the clinic prior to the beginning of the study. The participants were assured that their privacy and confidentiality would be fully protected. No identifiers were to be recorded in the questionnaires and database. The results of this study were to be presented only in an aggregate fashion.

Pregnancy in this study was considered to be unintended when it was reported to have been either mistimed (reported having wanted the pregnancy later) or unwanted (had not wanted to become pregnant then or later). All participants were asked whether they were using any type of contraceptive methods prior to this pregnancy and, if so, which method/ methods. Extremely young maternal age was defined as 16 years of age or younger. ${ }^{4}$

Statistical analysis was carried out with SPSS software (IBM Corporation, Armonk, NY, USA). Data were summarized as number (percentage) or mean \pm standard deviation when appropriate. On the basis of univariate analysis, variables potentially associated with unintended pregnancy and non-use of contraception including age, extremely young age versus older, gravidity (primigravidas versus multigravidas), and educational status (being in school versus having completed their education) were assessed. These variables were further included (if $P<0.20$ ) in a logistic regression analysis to determine which, if any, were jointly important in predicting unintended pregnancy and no contraceptive use prior to conception. Independent variables were considered significant if their effects on unintended pregnancy and non-use of contraception were statistically significant at the $95 \%$ level of significance. Colinearity between the factors included in the multivariate analyses was checked.

\section{Results}

During the study period, 200 participants were enrolled. Mean age and standard deviation was 17.2 \pm 1.2 years. Median age at first sexual intercourse was 16.0 years (interquartile range, 15-17 years). Eighteen (9.0\%) had first sexual intercourse at an age of 13 years or younger. The majority $(89.0 \%)$ of participants were primigravidas.

One hundred and eighteen (59.0\%) were currently in school. Eleven participants declared having no formal education. The levels of educational attainment among the remaining 71 participants were primary school (20), and high school or college (51). Table 1 displays the baseline characteristics, previous contraceptive practices, and sources of contraceptive information.

Seventy-five $(37.5 \%$; 95\% CI, 30.8-44.6) of the participants had never used any contraceptive methods. Of 125 participants who ever used contraception, regular use of contraceptives was reported in only 21 participants $(16.8 \%)$. Only two participants (1.0\%) had ever used an intrauterine device or subdermal implant. The participants' age was a significantly independent predictor for never using contraceptives. Extremely young adolescence was an independent factor predicting never using contraception (odds ratio [OR], 5.57; 95\% CI, 2.95-10.53) (Table 2).

Approximately two-thirds (69.0\%; 95\% CI, 62.1-75.3) of participants did not use contraception before getting this pregnancy. Extremely young adolescents were 6.4-times (95\% CI, 2.94-14.04) more likely than older participants to have not used contraception prior to getting this pregnancy (Table 3). 
Table I Baseline characteristics of 200 participants

\begin{tabular}{|c|c|}
\hline Characteristics & Number (percentage) \\
\hline \multicolumn{2}{|l|}{ Age (years) } \\
\hline$\leq 16$ & $81(40.5)$ \\
\hline 17 or older & $119(59.5)$ \\
\hline \multicolumn{2}{|l|}{ Gravidity } \\
\hline Primigravidity & I $78(89.0)$ \\
\hline Multigravidity & $22(11.0)$ \\
\hline \multicolumn{2}{|l|}{ Educational status } \\
\hline In school & II 8 (59.0) \\
\hline Completed their education & $82(41.0)$ \\
\hline \multicolumn{2}{|l|}{ Living situation } \\
\hline Lives with both parents & $109(54.5)$ \\
\hline Lives with mother or father & $13(6.5)$ \\
\hline Lives with sister and/or brother & $31(15.5)$ \\
\hline Lives with partner or husband & $43(21.5)$ \\
\hline Lives alone & $4(2.0)$ \\
\hline \multicolumn{2}{|l|}{ Contraceptives ever used* } \\
\hline Never & $75(37.5)$ \\
\hline OCPs & $47(23.5)$ \\
\hline Condom & $63(31.5)$ \\
\hline Emergency pills & $25(12.5)$ \\
\hline DMPA & $6(3.0)$ \\
\hline IUD & $\mathrm{I}(0.5)$ \\
\hline Implant & $\mathrm{I}(0.5)$ \\
\hline \multicolumn{2}{|c|}{ Contraceptives used before getting this pregnancy } \\
\hline None & $138(69.0)$ \\
\hline OCPs & $30(I 5.0)$ \\
\hline Condom & $15(7.5)$ \\
\hline Emergency pills & $13(6.5)$ \\
\hline DMPA & $4(2.0)$ \\
\hline \multicolumn{2}{|c|}{ Sources of contraceptive method information* } \\
\hline Teacher & $74(37.0)$ \\
\hline Friends & $58(29.0)$ \\
\hline Health care provider & $42(21.0)$ \\
\hline Parents & $29(14.5)$ \\
\hline Drug store & $20(10.0)$ \\
\hline Internet & $18(9.0)$ \\
\hline
\end{tabular}

Note: *Multiple answers allowed.

Abbreviations: DMPA, depot medroxyprogesterone acetate; IUD, intrauterine device; OCPs, oral combined pills.
One hundred and thirty-one $(65.5 \%$; 95\% CI, 58.5-72.1) participants did not think they were likely to become pregnant. Extremely young age was a significant independent predictor of not perceiving risk of getting this pregnancy (OR, 2.37; 95\% CI, 1.26-4.44) (Table 4).

One hundred and thirty-two $(66.0 \% ; 95 \%$ CI, 58.9-72.5) participants declared that they had not intended to become pregnant. Of all participants, 75 (37.5\%) wanted to terminate their pregnancy. Significant independent factors predicting unintended pregnancy were educational status and participants' age (Table 5).

\section{Discussion}

The results of this study indicate an underuse and inappropriate use of contraception among this study population. Approximately one-third (37.5\%) of participants never used any contraceptive methods. Among participants reported as ever using contraception, the rate of consistent use was only $17 \%$. Additionally, effective contraception such as longacting reversible contraception (LARC) was rarely used. Therefore, non-use, inconsistent use, and use of methods with high typical use failure rates were fundamental reasons leading to adolescent pregnancies in this study.

In this study, the only significant independent factor associated with whether pregnant adolescents had ever used contraceptives was participants' age. When adjusted by gravidity and educational status, extremely young pregnant adolescents were approximately six-times as likely as adolescents of 17 years or older to report as having never used any types of contraception (95\% CI, 2.95-10.53). In addition, a significantly higher proportion of pregnant adolescents in the extremely young age group reported as not using any contraception prior to becoming pregnant when compared to older participants

Table 2 Factors predicting never using contraception

\begin{tabular}{|c|c|c|c|c|}
\hline \multirow[t]{2}{*}{ Variables } & \multirow[t]{2}{*}{ Number (\%) } & \multirow[t]{2}{*}{$P$-value* } & \multicolumn{2}{|c|}{ Multivariate analyses } \\
\hline & & & Odds ratio & $95 \% \mathrm{Cl}$ \\
\hline Age (years) & & $<0.001$ & 5.57 & $2.95-10.53$ \\
\hline$\leq 16(n=8 I)$ & $50(6 I .7)$ & & & \\
\hline 17 or older $(n=119)$ & $25(21.0)$ & & & \\
\hline Gravidity & & 0.014 & 2.76 & $0.74-10.30$ \\
\hline Primigravidity $(n=\mid 78)$ & $72(40.4)$ & & & \\
\hline Multigravidity $(n=22)$ & $3(13.6)$ & & & \\
\hline Educational status & & 0.001 & 1.39 & $0.68-2.84$ \\
\hline In school $(n=|| 8)$ & $55(46.6)$ & & & \\
\hline Completed education $(n=82)$ & $20(24.4)$ & & & \\
\hline
\end{tabular}

Note: *From univariate analyses.

Abbreviation: $\mathrm{Cl}$, confidence interval. 
Table 3 Factors predicting no contraceptive use prior to getting this pregnancy

\begin{tabular}{|c|c|c|c|c|}
\hline \multirow[t]{2}{*}{ Variables } & \multirow[t]{2}{*}{ Number (\%) } & \multirow[t]{2}{*}{$P$-value* } & \multicolumn{2}{|c|}{ Multivariate analyses } \\
\hline & & & Odds ratio & $95 \% \mathrm{Cl}$ \\
\hline Age (years) & & $<0.001$ & 6.42 & $2.94-14.04$ \\
\hline$\leq 16(n=81)$ & $72(88.9)$ & & & \\
\hline 17 or older $(n=119)$ & $66(55.5)$ & & & \\
\hline Educational status & & 0.001 & 1.69 & $0.87-3.31$ \\
\hline In school $(\mathrm{n}=|| 8)$ & 92 (77.9) & & & \\
\hline Completed education $(n=82)$ & $46(56.1)$ & & & \\
\hline Gravidity & & 0.120 & 1.18 & $0.45-3.07$ \\
\hline Primigravidity $(\mathrm{n}=\mid 78)$ & $126(70.8)$ & & & \\
\hline Multigravidity $(\mathrm{n}=22)$ & $12(54.5)$ & & & \\
\hline
\end{tabular}

Note: *From univariate analyses.

Abbreviation: $\mathrm{Cl}$, confidence interval.

(adjusted OR, 6.42; 95\% CI, 2.94-14.04). Previous studies reported that one of the common reasons leading to inappropriate use of contraception was unawareness of the risk of pregnancy. ${ }^{10,11}$ In this study, a remarkably high proportion of participants perceived themselves at low risk of becoming pregnant, particularly among extremely young adolescents (76.5\%). Thus, a high rate of non-use, inconsistent use, and use of contraceptives with high failure rates noted in the study may be anticipated, particularly among extremely young adolescents.

The result of this analysis together with the previously reported findings indicated that the majority of pregnancies occurring among adolescents were unintended. ${ }^{12-14}$ In this study, the educational status and age of extremely young adolescents were significant independent contributors to a high rate of unintended pregnancy. Getting pregnant during school can cause a participant to be expelled from school or become a dropout of the school. Unsurprisingly, participants who were still in school were approximately seven-times more likely than those who had completed their education to have unintended pregnancy $(85.6 \%$ versus $37.8 \%$; adjusted OR, 6.17; 95\% CI, 3.27-13.75).
In the present study, extremely young pregnant adolescents carried a significantly higher risk of unintended pregnancy than older adolescents $(90.1 \%$ versus $49.6 \%$; adjusted OR, $5.76 ; 95 \%$ CI, 2.42-13.70). The high rate of unintended pregnancy among extremely young adolescents might be due to the fact that younger participants were less able to be supported by their families and be cared for than older adolescents.

LARC was rarely used among adolescents and young women. ${ }^{15}$ Only $1 \%$ of participants in this study had ever used intrauterine devices or subdermal implants. In a large prospective cohort study to promote use of LARC as a means of reducing unintended pregnancy, participants younger than 21 years who used oral combined pills, patches, or rings were almost twice as likely as older participants to experience unintended pregnancy. ${ }^{16}$ The effectiveness of LARC is high among adolescents. ${ }^{16,17}$ Additionally, rates of early discontinuation of LARC among adolescents were notably low. ${ }^{18}$ Thus, it is evident that LARC is the first-line contraceptive option for adolescents and young women. Further study evaluating the effective interventions for implementing LARC among adolescents therefore is warranted.

Table 4 Predictor of unawareness of the risk of pregnancy

\begin{tabular}{|c|c|c|c|c|}
\hline \multirow[t]{2}{*}{ Variables } & \multirow[t]{2}{*}{ Number (\%) } & \multirow[t]{2}{*}{$P$-value* } & \multicolumn{2}{|c|}{ Multivariate analyses } \\
\hline & & & Odds ratio & $95 \% \mathrm{Cl}$ \\
\hline Age (years) & & 0.007 & 2.37 & I.26-4.44 \\
\hline$\leq 16(n=8 \mathrm{I})$ & $62(76.5)$ & & & \\
\hline 17 or older $(n=119)$ & $69(57.9)$ & & & \\
\hline Educational status & & 0.020 & 1.48 & $0.77-2.82$ \\
\hline In school (n=I|8) & $85(72.0)$ & & & \\
\hline Completed education $(\mathrm{n}=82)$ & $46(56.1)$ & & & \\
\hline Gravidity & & 0.036 & 2.07 & $0.83-5.19$ \\
\hline Primigravidity (n=I78) & I2I (67.9) & & & \\
\hline Multigravidity $(\mathrm{n}=22)$ & $10(45.5)$ & & & \\
\hline
\end{tabular}

Note: *From univariate analyses.

Abbreviation: $\mathrm{Cl}$, confidence interval. 
Table 5 Factors predicting unintended pregnancy

\begin{tabular}{|c|c|c|c|c|}
\hline \multirow[t]{2}{*}{ Variables } & \multirow[t]{2}{*}{ Number (\%) } & \multirow[t]{2}{*}{$P$-value* } & \multicolumn{2}{|c|}{ Multivariate analyses } \\
\hline & & & Odds ratio & $95 \% \mathrm{Cl}$ \\
\hline Educational status & & $<0.001$ & 6.71 & $3.27-13.75$ \\
\hline In school (n=||8) & $101(85.6)$ & & & \\
\hline Completed education $(n=82)$ & $31(37.8)$ & & & \\
\hline Age (years) & & $<0.001$ & 5.76 & $2.42-13.70$ \\
\hline$\leq 16(n=8 I)$ & $73(90.1)$ & & & \\
\hline 17 or older $(n=119)$ & $59(49.6)$ & & & \\
\hline Gravidity & & 0.008 & 1.45 & $0.5 I-4.1 I$ \\
\hline Primigravidity $(\mathrm{n}=\mid 78)$ & $123(69.1)$ & & & \\
\hline Multigravidity $(n=22)$ & $9(40.9)$ & & & \\
\hline
\end{tabular}

Note: *From univariate analyses.

Abbreviation: $\mathrm{Cl}$, confidence interval.

Some previous studies showed that exposure to health providers had no significant impact on women's knowledge of contraceptive effectiveness and patterns of practice. ${ }^{7,9}$ Communication failure, poor contraceptive counseling skills, and the incomplete knowledge of counselors about updated contraceptive capabilities have been highlighted as potential contributors of using a less effective contraceptive method or of an inappropriate use. ${ }^{7,9}$ In this study, the majority of participants (58.0\%) received contraceptive information from their teachers and health care providers which might generally be considered as reliable sources of contraceptive information. The underuse of effective contraceptive methods among the current participants, however, still existed. The exact nature of this unfavorable finding requires further evaluation in research if effective prevention of adolescent pregnancy is to be established.

This study is not without limitations. Firstly, baseline knowledge, attitudes, beliefs about contraceptive use, and underlying reasons for underuse of LARC among the participants were not evaluated in this study. Secondly, some information that might impact contraceptive practice, ie, male partner's characteristics, socioeconomic characteristics of the couple, detailed characteristics of counselors, and accessibility to contraceptive and abortion services, were not available. Finally, this study was conducted among pregnant adolescents at antenatal clinics, and thus generalizability of the study results to other population settings should be meticulously viewed. However, the results of this study highlight the magnitude of unintended pregnancy and its associated factors among pregnant adolescents in Thailand - a region with a high prevalence of unintended pregnancy.

\section{Conclusion}

In conclusion, non-use and use of contraceptive methods with high failure rates (eg, oral combined pills and condom) were major reasons leading to adolescent pregnancies in this study. Participants' age was a significant independent factor associated with non-use of contraceptives. Educational status and age of the participants were significant independent predictors for unintended pregnancy.

\section{Acknowledgment}

We would like to acknowledge Professor James A Will for editing the manuscript via Publication Clinic, Khon Kaen University.

\section{Disclosure}

The authors report no conflicts of interest in this work.

\section{References}

1. Ganchimeg T, Ota E, Morisaki N, et al. Pregnancy and childbirth outcomes among adolescent mothers: a World Health Organization multicountry study. BJOG. 2014;121 Suppl 1:40-48.

2. Watcharaseranee N, Pinchantra P, Piyaman S. The incidence and complications of teenage pregnancy at Chonburi Hospital. J Med Assoc Thai. 2006;89 Suppl 4:S118-S123.

3. Thaithae S, Thato R. Obstetric and perinatal outcomes of teenage pregnancies in Thailand. J Pediatr Adolesc Gynecol. 2011;24(6): 342-346.

4. Chantrapanichkul P, Chawanpaiboon S. Adverse pregnancy outcomes in cases involving extremely young maternal age. Int J Gynaecol Obstet. 2013;120(2):160-164.

5. Joyce T, Kaestner R, Korenman S. The stability of pregnancy intentions and pregnancy-related maternal behaviors. Matern Child Health J. 2000;4(3):171-178.

6. Chaturachinda K. Unsafe abortion in Thailand: Role of RTCOG. Thai J Obstet Gynaecol. 2014;22(1):2-7.

7. Lamvu G, Steiner MJ, Condon S, Hartmann K. Consistency between most important reasons for using contraception and current method used: the influence of health care providers. Contraception. 2006;73(4): 399-403.

8. Rutherford J, Holman R, MacDonald J, Taylor A, Jarrett D, Bigrigg A. Low literacy: a hidden problem in family planning clinics. J Fam Plann Reprod Health Care. 2006;32(4):235-240.

9. Dehlendorf C, Levy K, Ruskin R, Steinauer J. Health care providers' knowledge about contraceptive evidence: a barrier to quality family planning care? Contraception. 2010;81(4):292-298. 
10. Ayoola AB, Nettleman M, Brewer J. Reasons for unprotected intercourse in adult women. $J$ Womens Health (Larchmt). 2007;16(3):302-310.

11. Biggs MA, Foster DG. Misunderstanding the risk of conception from unprotected and protected sex. Womens Health Issues. 2013;23(1): e47-e53.

12. Rosengard C, Phipps MG, Adler NE, Ellen JM. Adolescent pregnancy intentions and pregnancy outcomes: a longitudinal examination. $J$ Adolesc Health. 2004;35(6):453-461.

13. Areemit R, Thinkhamrop J, Kosuwon P, Kiatchoosakun P, Sutra S, Thepsuthammarat K. Adolescent pregnancy: Thailand's national agenda. J Med Assoc Thai. 2012;95 Suppl 7:S134-S142.

14. Sriprasert I, Chaovisitsaree S, Sribanditmongkhol N, Sunthormlomsiri N, Kietpeerakool C. Unintended pregnancy and associated risk factors among young pregnant women. Int J Gynaecol Obstet. Epub 2014 Oct 16 .
15. Moreau C, Bohet A, Hassoun D, Teboul M, Bajos N; FECOND Working Group. Trends and determinants of use of long-acting reversible contraception use among young women in France: results from three national surveys conducted between 2000 and 2010. Fertil Steril. 2013; 100(2):451-458.

16. Winner B, Peipert JF, Zhao Q, et al. Effectiveness of long-acting reversible contraception. N Engl J Med. 2012;366(21):1998-2007.

17. Secura GM, Madden T, McNicholas C, et al. Provision of no-cost, longacting contraception and teenage pregnancy. NEnglJMed.2014;371(14): $1316-1323$

18. Grunloh DS, Casner T, Secura GM, Peipert JF, Madden T. Characteristics associated with discontinuation of long-acting reversible contraception within the first 6 months of use. Obstet Gynecol. 2013;122(6): $1214-1221$

\section{Publish your work in this journal}

The International Journal of Women's Health is an international, peerreviewed open-access journal publishing original research, reports, editorials, reviews and commentaries on all aspects of women's healthcare including gynecology, obstetrics, and breast cancer. The manuscript management system is completely online and includes a very quick and fair peer-review system, which is all easy to use. Visit http://www.dovepress.com/testimonials.php to read real quotes from published authors.

Submit your manuscript here: http://www.dovepress.com/international-journal-of-womens-health-journal 